\title{
Prescription drug coverage: An essential service or a fringe benefit?
}

\section{Robyn M. Tamblyn}

$\infty \quad$ See related article page 1335

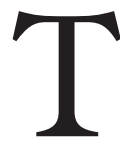
he study in this issue by Anis and colleagues on user fees for prescription drugs ${ }^{1}$ highlights one of the most salient contradictions in the Canadian health care system. Equal access to medically necessary services is a cherished and protected principle of the Canada Health Act. But when it comes to prescription drugs, they are only considered medically necessary if given in a hospital setting. This inconsistency in policy creates daily paradoxes in care delivery that systematically undermine efforts to extend our hospital-centric system into ambulatory and home-care environments.

Consider the following notional example: Mr. J, a 56year-old man, is admitted to hospital with an acute myocardial infarction, undergoes emergency angioplasty, is started on treatment with a calcium-channel blocker, $\beta$-blocker, lipid-reducing drug and ASA, and is discharged 3 days later as part of a state-of-the-art early discharge follow-up program. The total cost for emergency and hospital care is \$15 000 (\$5000 for the angioplasty and \$10 o0o for the hospital stay and services, which include $\$ 900$ for 3 days of intravenous and oral drug therapy). The cost paid by the patient is zero, regardless of which province he's in - a testimony to the success of the Canada Health Act in facilitating equitable access to medically necessary care across the country. But after discharge, the same medically necessary drug treatment begun in hospital will cost the patient \$I400 per year if he lives in New Brunswick, $\$ 800$ in Saskatchewan and \$200 in British Columbia. Why? Because although each province has instituted some form of drug insurance coverage to rectify the gap in the provision of medically necessary drugs, the programs vary in comprehensiveness, eligibility and access. This patchwork of programs results in considerable differences in out-of-pocket expenses for patients with the same health problem. ${ }^{2}$

At present, provincial insurance programs apply a double standard - they institute user fees for prescription drugs, as a way of controlling unnecessary use, but not for medical or hospital services because of prohibitions by the Canada Health Act. It is difficult to justify the continued application of this double standard. First, angioplasty is no more important or worthy of first-dollar coverage than the $\beta$-blocker therapy that could have obviated its need. Second, decades of research have shown that user fees do not achieve the intended pur- pose. People will reduce the use of both essential and less essential drugs when asked to pay for part of the cost, or they will seek free drug treatment through admission to hospital or a long-term care facility, as was observed by Anis and colleagues ${ }^{1}$ and others. ${ }^{3}$

\section{The national drug strategy ignores the fundamental inequity between provinces.}

Anis and colleagues used administrative data collected by the Ministry of Health of British Columbia to look at the pattern of utilization of health care services among $B C$ residents 65 years of age and older who had rheumatoid arthritis. Elderly patients in British Columbia must pay the dispensing fee for prescription medications, but not the ingredient costs, to a maximum of $\$ 200$ each year, after which the provincial drug insurance plan covers all fees for the remainder of the year. The authors found that patients had fewer prescriptions filled, but used more physician services, during the cost-sharing period (the period before they reached the $\$ 200$ maximum) than during the free period (when all drug costs were covered by the province). Although the patients were equally likely to be admitted to hospital during the 2 periods, there were more admissions per month during the cost-sharing period than during the free period among patients who were admitted to hospital. Other studies have also shown that immediate savings in drug treatment are offset later by increases in the rate and costs of medical visits, emergency care and hospital admissions. ${ }^{3}$ Indeed, the $\mathrm{BC}$ study probably underestimated the magnitude of the increase in use of medical and hospital services, because only patients who could afford to pay the $\$ 200$ annual maximum to receive free medications were included.

The need for reform in prescription drug coverage policy has been recognized.4,5 In Canada, the federal agenda for health care renewal includes the institution of a national pharmaceuticals strategy aimed at providing affordable access to needed drug therapy. ${ }^{4}$ Although the national strategy 
goes beyond many prior policy reforms in recognizing and addressing the challenges in optimizing the cost-effective use of prescription drugs, it does not address the fundamental inequity between provinces in access to essential prescription drugs. ${ }^{4}$ The 9-point program that is to be instituted over the next ro years would have little, if any, impact on the costs of essential medications for Mr. J. Even the prospect of catastrophic drug coverage is to be assessed relative to potential costs with no promise of implementation.

The persistent annual increase in prescription drug expenditures of $10 \%-15 \%$ per year ${ }^{6,7}$ may explain the federal government's reticence to provide a more definitive policy response to obvious inequities in the Canadian health care system. Prescription drug expenditures have surpassed $\$ 18$ billion annually in Canada and are estimated to exceed $\$ 200$ billion in the United States.5,6 Prescription of new drugs and an increase in the number of drugs per person are the primary cost drivers. ${ }^{8}$ Another factor is the 1987 and 1992 federal government decision to extend and strengthen patent protection to foster a healthy pharmaceutical industry, which is now being felt in health care:9,10 expenditures on patentprotected medication have increased dramatically over the decade, from $43.8 \%$ to $67.4 \%$ of total drug costs. ${ }^{11}$

Over- and underuse of prescription medications, errors in prescribing, dispensing and administration, and suboptimal adherence to essential treatment compromise the potential benefits of drug treatment ${ }^{12}$ and in turn contribute to avoidable health care expenditures in Canada. Methods of optimizing the cost-effective use of prescription drugs are needed to sustain equitable access to prescription drugs for Canadians. The controversial Medicare Reform Bill, which promises $\$ 400$ billion in prescription drug coverage over the next ro years for elderly Americans, has provided one policy option for cost control that heavily subsidizes the costs of prescribing decisions made by physicians and drug costs established by the industry, with user fees to be paid by patients. ${ }^{13}$ It is time for Canada to implement more aggressive and creative policy action to provide eq- uitable access to essential prescription drugs. This action should encompass efforts to minimize inappropriate and inefficient prescribing practices; it should also revisit Canada's pharmaceutical patent protection laws and the regulatory framework for initial and continuing drug approval.

Robyn Tamblyn is Professor in the Departments of Medicine and of Epidemiology and Biostatistics, McGill University, Montréal, Que.

Competing interests: None declared.

\section{REFERENCES}

I. Anis AH, Guh DP, Lacaille D, et al. When patients have to pay a share of drug costs: effects on frequency of physician visits, hospital admissions and filling prescriptions. CMAJ 2005;I73(II):1335-9.

2. Grootendorst P. Beneficiary cost-sharing under Canadian provincial prescription drug benefit programs: history and assessment. Can J Clin Pharmacol 2002;9:79-99.

3. Lexchin J, Grootendorst P. Effects of prescription drug user fees on drug and health services use and on health status in vulnerable populations: a systematic review of the evidence. Int J Health Serv 2004;34:I0I-22.

4. A ro-year plan to strengthen health care. Ottawa: Office of the Prime Minister; 2004 Sept I6. Available: pm.gc.ca/eng/news.asp?id=260 (accessed 2005 Oct 2I).

5. Iglehart JK. Medicare and prescription drugs. N Engl J Med 200I;344:I0I0-5.

6. Morgan S. Canadian prescription drug costs surpass $\$ 18$ billion [editorial]. CMAJ 2005;172(I0):1323-4.

7. Menon D. Pharmaceutical cost control in Canada: Does it work? Health Aff 2001; 20:92-I03.

8. Anderson GM, Kerluke KJ, Pulcins IR, et al. Trends and determinants of prescription drug expenditures in the elderly: data from the British Columbia Pharmacare Program. Inquiry 1993;30:199-207.

9. Pazderka B. Patent protection and pharmaceutical R\&D spending in Canada. Can Public Policy 1999;25:29-46.

Io. Lexchin J. Intellectual property rights and the Canadian pharmaceutical marketplace: Where do we go from here? Int J Health Serv 2005;35:237-56.

II. PMPRB 2002 annual report. Ottawa: Patented Medicine Prices Review Board; 2002. Available: www.pmprb-cepmb.gc.ca/english/View.asp? $\mathrm{x}=223 \& \mathrm{mp}=9 \mathrm{I}$ (accessed 2005 Oct 2I).

I2. Tamblyn R, Perreault R. Prescription drug use and seniors. Can J Aging 2000;19: I $43-75$.

13. Iglehart JK. The new Medicare prescription-drug benefit - a pure power play. $N$ Engl J Med 2004;350:826-33.

Correspondence to: Dr. Robyn M. Tamblyn, Clinical and Health Informatics Research Group, McGill University, II4o Pine Ave. W, Montréal QC H3A IA3; fax 514 843-I55I; robyn.tamblyn@mcgill.ca

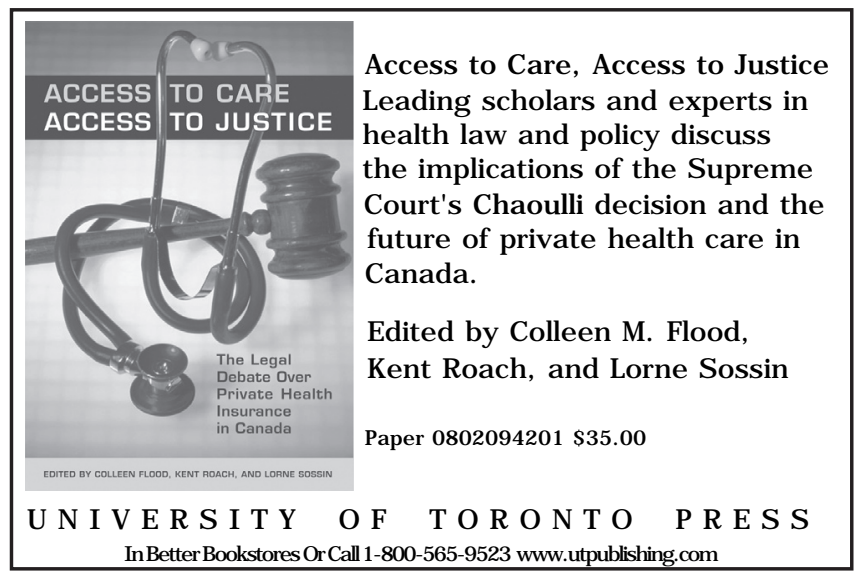

CMAJ - NOVember 22, $2005 \cdot 173(11) \quad \mid \quad 1344$ 